\title{
КОГНИТИВНЫЙ АСПЕКТ ПЕРЕВОДА ФРАЗЕОЛОГИЧЕСКИХ ЕДИНИЦ
}

\section{COGNITIVE ASPECT OF PHRASEOLOGICAL UNITS TRANSLATION \\ K. Bashkirova \\ L. Gatiyatullina \\ I. Guryanov}

Summary: Translation of phraseological units has always presented a certain difficulty for translators. First of all, this is due to expressive and emotionally brightly coloured phrases that relate to a specific style of speech and most often carry the national features of certain cultures. Secondly, the rethought and metaphorical images of phraseological units require the translator to know not only the lexical fund of the language, but also knowledge of certain extralinguistic factors. In this study, the authors set the task to find out how phraseological units' complicate translation. With the help of the Translog II software, an experiment was carried out among 30 second-year students of the Kazan Federal University, studying in the specialty "Philology. Translation studies ". Students were divided into two groups: control and experimental, 15 people each. Both groups were given the task of translating 5 sentences from English into Russian. In the control group, the subjects translated sentences without phraseological units, in the experimental group the same sentences were modified using phraseological units. The analysis of the results of the experiment allowed the authors to reveal how the phraseological units increase the time spent on the translation of sentences.

Keywords: phraseological unit, translation, cognitive linguistics, translog, experiment.
Башкирова Карина Александровна

Соискатель, старший преподаватель, Казанский (приволжский) федеральный университет

c.b-carina@yandex.ru

Гатиятуллина Лиана Фаргатовна

Ассистент, Казанский (приволжский) федеральный университет lianfar@mail.ru

Гурьянов Игорь Олегович К.филол.н., доцент, Казанский (приволжский) федеральный университет

igor.goor@gmail.com

Аннотация: Перевод фразеологических единиц всегда представлял определенную трудность для переводчиков. В первую очередь, это связано с экспрессивными и эмоционально ярко окрашенными оборотами, которые относятся к конкретному стилю речи и чаще всего несут в себе национальные черты определенных культур. Во-вторых, переосмысленные и метафорические образы ФЕ требуют от переводчика знания не только лексического фонда языка, но и знания определенных экстралингвистических факторов. В данном исследовании авторами была поставлена задача выяснить насколько фразеологические единицы осложняют перевод. С помощью программного обеспечения «Translog Il» был проведен эксперимент среди 30 студентов второго курса Казанского федерального университета, обучающихся по специальности «Филология. Переводоведение». Студенты были разделены на две группы: контрольную и экспериментальную по 15 человек в каждой. 0беим группам было дано задание на перевод 5 предложений с английского языка на русский. В контрольной группе испытуемые переводили предложения без фразеологических единиц, в экспериментальной группе те же самые предложения были модифицированы с помощью ФЕ. Анализ результатов эксперимента позволил авторам выявить насколько фразеологические единицы увеличивают время, затраченное на перевод предложений.

Ключевые слова: фразеологическая единица, перевод, когнитивная лингвистика, translog, эксперимент.

явить количественные характеристики, позволяющие измерить насколько фразеологические единицы, осложняют перевод и каким образом можно измерить когнитивный потенциал данных единиц. Говоря о многочисленных когнитивных характеристиках пригодных для количественного подсчета, был выбран косвенный признак - количество времени, затраченное на перевод. Благодаря современным компьютерным программам стало возможным отследить весь процесс письменного перевода, скорость реакции, возможные переводческие решения, ошибки, опечатки и другие элементы когнитивной деятельности переводчика.

Под когнитивной деятельностью индивида мы берем за основу утверждение Л.В. Савицкой: «процессы, кото- 
рые происходят в мозге человека, отвечающие за переработку полученной информации, вследствие которых образуются особые структуры ... язык представляет собой систему знаков, которые участвуют в кодировании и передачи информации, то есть сначала разрабатывается информация о мире и лишь потом она вербализуется» [4]. Исходя из этого определения, процесс перевода является процессом кодирования и декодирования информации в другой языковой системе. В свою очередь, фразеологические единицы представляют собой дополнительно зашифрованные кластеры, несущие в себе культурно-историческую информацию, на расшифровку и перекодировку которой может потребоваться значительное количество временных ресурсов.

Только переводчик решает, какой переводческой стратегией стоит воспользоваться, что в свою очередь зависит от поставленной цели: сохранение значения самой фразеологической единицы, но потеря экспрессивности, либо передача выразительной окраски фразы в ущерб семантике [2].

Еще одним фактором, осложняющим перевод фразеологических единиц, является значительное количество вариантов перевода фразеологизмов. По способу перевода все ФЕ можно разделить на две большие группы на эквивалентные (полные и частичные эквиваленты и аналоги) и безэквивалентые (описательный и лексемный переводы) [1].

С опорой на данные теоретические выкладки исследователями была сформулирована гипотеза, требующая экспериментального подтверждения - фразеологические единицы, значительно осложняют перевод предложений на другой язык и увеличивают общее время перевода.

\section{Методы исследования}

Программа Translog II применяется для исследования процессов перевода лингвистических явлений (например, перевода метафор, идиом и т.д.). Таким образом, данное программное обеспечение служит для получения объективных данных о процессах перевода.

Исследователями были отобраны две группы студентов 2 курса, общим количеством 30 человек, прошедшие тестирование владения английским языком на уровень Intermediate - Upper-intermediate.

Студенты были разделены с помощью генератора случайных чисел на контрольную и экспериментальную группы. Обеим группам было предложено перевести по 5 предложений с использованием программы «Translog II».

Ниже приведены предложения для контрольной группы:

1. Even though we have worked really hard and put all the efforts into it, the failure of business company wasn't a big surprise to us. We expected something like this because our competitors have demonstrated a really good job.

2. Ben was invited to his boss but he was nervous waiting before his boss would talk to him. The conversation was supposed to be a serious one.

3. Clarie had a serious argument with her friend. The moment they have met each other Clarie told her everything she wanted to. Nevertheless, they managed to deal with this disagreement.

4. Tom has everything you can dream about because he worked very hard to get it all.

5. The detectives agreed that this case was not as easy as it seemed from the first sight. Only after several conversations with witnesses they have got some ideas on what had happened. Very soon afterwards the suspect was caught.

Характеристики текста для контрольной группы: среднее количество слов в предложении составляет 30,2 слова, при этом знаменательных слов было обнаружено 19,8, служебных - 10,4 (всего слов 151, знаменательных 99, служебных - 52).

Для студентов же экспериментальной группы данные предложения были модифицированы с помощью фразеологических единиц.

Характеристики текста для экспериментальной группы: среднее количество слов в предложении составляет 33,5 слова, при этом знаменательных слов было обнаружено 19,4, служебных - 14,1 (всего слов 170, знаменательных - 116, служебных - 61).

1. Even though we have worked really hard and put all the efforts into it, the failure of business company did not come as a bolt from the blue to us. We expected something like this because our competitors have demonstrated a really good job.

2. Ben was invited to his boss but he was forced cool his heels before his boss would talk to him. The conversation was supposed to be a serious one.

3. Clarie had a serious argument with her friend. The moment they have met each other Clarie gave her a piece of her mind. Nevertheless, they managed to deal with this disagreement.

4. Tom has everything you can dream about, but he wasn't born with a silver spoon in his mouth. He worked very hard to get it all.

5. The detectives agreed that this case was not as easy as it seemed from the first sight. Only after several conversations with witnesses they have thrown light on it. Very soon afterwards the suspected was caught. 


\section{Результаты}

В ходе анализа экспериментальных данных было выявлено, что наличие фразеологических единиц в предложении значительно увеличивает количество времени, затраченного на перевод.

Ниже приведены данные о средних временных показателях в контрольной и экспериментальной группах:

\begin{tabular}{|c|c|c|}
\hline № предложения & $\begin{array}{c}\text { Перевод предложения } \\
\text { без использования } \\
\text { фразеологической } \\
\text { единицы, сек }\end{array}$ & $\begin{array}{c}\text { Перевод предложения } \\
\text { с использованием } \\
\text { фразеологической } \\
\text { единицы, сек }\end{array}$ \\
\hline Предложение 1 & 86,2 & 149,1 \\
\hline Предложение 2 & 49,5 & 105 \\
\hline Предложение 3 & 37,1 & 74,5 \\
\hline Предложение 4 & 34,1 & 74,1 \\
\hline Предложение 5 & 58,8 & 98,6 \\
\hline
\end{tabular}

Из приведённых выше данных мы можем получить следующие показатели: среднее время, затраченное на перевод предложений без использования фразеологических единиц, составило 53,14 секунд; среднее время, затраченное на перевод предложений с использованием фразеологических единиц, составило 100,26 секунд. Таким образом, использование фразеологических единиц в данном исследовании показало увеличение времени перевода на 47,12 секунд.

Следовательно, мы приходим к выводу, что в присутствие в тексте фразеологических единиц действительно осложняет общее восприятие текста и замедляет процесс перевода. Это дает нам право считать нашу гипотезу подтвержденной.

\section{ОбсужАение}

Translog II помог установить, что в среднем перевод одного предложения занимает у студентов 98 секунд, из которых 32,6 приходится на перевод устойчивой единицы, что составляет почти треть от времени, затраченного на перевод всего предложения. При переводе контрольных предложений со свободными сочетаниями слов, студенты потратили в среднем 67,4 секунды. Нами было учтено и время, потраченное студентами на исправления, замедляющие процесс перевода, и непосредственно сами исправления.

Наряду со временем, затраченным на перевод предложений с фразеологическими единицами, было выявлено какими способами студенты переводили данные единицы. Так, значительное количество студентов использовало аналоги ФЕ (10 случаев) (to give a piece of mind (сл.перевод: высказать недовольство) - высказать все, что думается; as a bolt from the blue - как гром среди ясного неба), хотя также были обнаружены такие типы перевода как эквивалентный (15 случаев) (clear one's name - очистить имя) и лексический перевод (as a bolt from the blue (сл.перевод: как гром среди ясного неба) неожиданность).

Интересен тот факт, что были обнаружены случаи, когда при переводе ФЕ использовалось свободное сочетание (27 случаев) или ФЕ, которые не соответствуют значению оригинальной ФЕ (8 случаев). (to throw a light (сл.перевод: пролить свет на что-либо) - дойти до истины, to cool one's hills (сл.перевод: томиться в ожидании) - сердце ушло в пятки, или перестать дурачиться). Это можно объяснить недостаточным количеством лингвокультурных и лексических знаний, что осложняет задачу распознавания и грамотного перевода ФЕ.

\section{Зак^ючение}

В рамках нашего исследования мы рассмотрели когнитивный аспект перевода фразеологических единиц. C помощью программного обеспечения Translog II нам удалось получить количественные результаты, показывающие степень осложнения перевода текстов, содержащих фразеологизмы.

В текстах служебные слова составляют $42 \%$ от общего количества и знаменательные слова составляют 58\% соответственно. Несмотря на то, что служебные слова для носителя языка не представляют сложности при распознавании и употреблении, при переводе мы наблюдаем обратную ситуацию. Так, Слепович В.С., наряду с другими учеными (Гуськова Т.И., Русина Ю.Н. и др.), выделяют служебные слова как наиболее сложные для перевода на разносистемные языки.

В экспериментальных текстах соотношение устойчивых сочетаний слов - ФЕ составляет 33\%, свободные сочетания слов занимают $67 \%$ от общего числа словосочетаний.

Несмотря на преобладание в предложениях свободных сочетаний слов, большее количество времени затрачивается переводчиком на перевод устойчивых сочетаний слов. Так, примерно треть времени от общего количества времени, потраченного на перевод, отводится испытуемыми на перевод устойчивых сочетаний слов.

Это свидетельствует о том, что наличие устойчивых сочетаний действительно влияет на скорость перевода текстов, так как требуется больше времени на обдумывание и согласование всех смысловых отрезков.

Целью данного исследования было доказательство 
выдвинутой гипотезы о том, что фразеологические единицы, встречающиеся на пути переводчика, замедляют процесс перевода. Гипотеза исследования была подтверждена экспериментально.

Так, мы установили, что фразеологические единицы уменьшают скорость перевода, так как требуется время на осмысление и выбор подходящего переводческого решения. Экспериментально было доказано, что средняя скорость перевода текста с наличием фразеологических оборотов стала медленнее на 47,12 секунд. Это время ушло на обдумывание и попытку подобрать соответствующую идиому в языке-реципиенте.
Экспериментальное исследование также продемонстрировало нам способы перевода фразеологизмов. Чаще всего участники эксперимента выбирали свободное сочетание в качестве интерпретации оригинальной ФЕ. Однако случаи использования фразеологических эквивалентов и аналогов имели место в переводах. Основываясь на результатах, полученных в ходе экспериментального исследования, можно заключить, что когнитивный потенциал фразеологических единиц достаточно обширен и являет собой трудный аспект перевода, требующий от переводчика экстралингвистических знаний и увеличивающий время, затраченное на перевод.

\section{ЛИТЕРАТУРА}

1. Аманова Г.Т. Культурно-когнитивный аспект перевода // Молодой ученый. — 2015. — №10. — С. 1366-1367.

2. Арсентьева Е.Ф. Контекстуальное использование фразеологических единиц. / Е.Ф. Арсентьева. - Казань:Хэтер, 2009. - 168 с.

3. Гуськова Т.И., Зиборова Г.М. Трудности перевода общественно-политического текста с английского языка на русский/ Издательство: М.: Российская политическая энциклопедия (РОССПЭН); Издание 3-е, испр. и доп.- 2000. - 228 с.

4. Савицкая Л.В. Лингвистика и межкультурная коммуникация. // Когнитивный аспект перевода в свете межкультурной коммуникации. - 2013. - C. 114-120.

5. Слепович В.С. Перевод (английский <-> русский язык). Учебник. Минск: Тетралит, 2014. - 336 c.

6. Davletbaeva Diana N., Bashkirova Karina A., Larionova Elena S., Structural and pragmatic features of english, russian and tatar code-switching//MODERN JOURNAL OF LANGUAGE TEACHING METHODS. - 2017. - Vol.7, Is.12. - P.65-71.

7. Lakoff G., Johnson M. Metaphors we live by. Chicago: University of Chicago Press, 1990. 415 p.

( ) Башкирова Карина Александровна (c.b-carina@yandex.ru), Гатиятуллина Лиана Фаргатовна (lianfar@mail.ru),

. Гурьянов Игорь Олегович (igor.goor@gmail.com)

Журнал «Современная наука: актуальные проблемы теории и практики»



